\title{
HYPERCYCLICITY AND WEYL TYPE THEOREMS FOR OPERATOR MATRICES
}

\author{
IL JU AN AND JAESEONG HEO
}

Abstract. In this paper, we study the hypercyclicity and supercyclicity for operator matrices in the class $\mathscr{S}$ consisting $2 \times 2$ operator matrices with $(1,2)$-entries having closed range. Under some conditions, we find the necessary and sufficient conditions for $2 \times 2$ operator matrices in the class $\mathscr{S}$ for which Weyl's theorem, Browder's theorem, $a$-Weyl's theorem or $a$-Browder's theorem hold.

Mathematics subject classification (2010): Primary 47A53, 47A55, 47A10.

Keywords and phrases: $2 \times 2$ operator matrices, Browder essential approximate point spectrum, Weyl's theorem, $a$-Weyl's theorem, $a$-Browder's theorem.

\section{REFERENCES}

[1] P. AiEnA, Fredholm and local spectral theory with applications to multipliers, Kluwer Academic Pub., 2004.

[2] Alatancang, G. Hou And G. Hai, Perturbation of spectra for a class of $2 \times 2$ operator matrices, Acta Math. App. Sincica, 28 (2012), 711-720.

[3] F. Bayart and E. Matheron, Dynamics of linear operators, Cambridge Tracts in Mathematics, 179. Cambridge University Press, Cambridge, 2009.

[4] S. BERBERIAN, An extension of Weyl's theorem to a class of not necessarily normal operators, Michigan Math. J. 16 (1969), 273-279.

[5] X. CAO AND B. MENG, Essential approximate point spectra and Weyl's theorem for operator matrices, J. Math. Anal. Appl., 304 (2005), 759-771.

[6] X. CAO, M. GuO AND B. MENG, Weyl's theorem for upper triangular operator matrices, Linear Algebra Appl., 420 (2005), 61-73.

[7] X. CAO, Weyl type theorems and hpercyclic operators II, Proc. Amer. Math. Soc. 135 (2007), 17011708.

[8] L. A. CobuRn, Weyl's theorem for nonnormal operators, Michigan Math, J. 13 (1966), 285-288.

[9] R. CURTO AND Y. M. HAN, Weyl's theorem, a-Weyl's theorem, and local spectral theory, J. London Math. Soc. (2) 67 (2003), 499-509.

[10] R. CURTO AND Y. M. HAN, Weyl's theorem for algebraically paranormal operators, Integral Equations Operator Theory 47 (2003), 307-314.

[11] J. HEO, E. KIM AND S. KIM, q-frequent hypercyclicity in an algebra of operators, To appear in Bull. Korean Math. Soc.

[12] D. HerRero, Limits of hypercyclic and supercyclic operators, J. Functional Analysis, 99 (1991), $179-190$.

[13] K. Laursen and M. Neumann, An introduction to local spectral theory, London Mathematical Society Monographs, Oxford University Press, New York, 2000.

[14] W. LEE, Weyl's theorem for operator matrices, Integral Equations Operator Theory 32 (1998), 319331.

[15] W. LEE, Weyl spectra of operator matrices, Proc. Amer. Math. Soc. 129 (2001), 131-138. 